\title{
Polarographic Behavior of Nicotinamide in Surfactant Media and Its Determination in Cetyltrimethylammonium Bromide Surfactant System
}

\author{
Rahul M. KotKar and Ashwini K. SRIVASTaVA ${ }^{\dagger}$ \\ Department of Chemistry, University of Mumbai, Vidyanagari, Santacruz (East), Mumbai-400 098, India
}

\begin{abstract}
The behavior of nicotinamide has been studied by differential pulse polarography and cyclic voltammetry in the presence of certain ionic and nonionic surfactants, viz. cetyltrimethylammonium bromide (CTAB), sodium dodecylsulfate (SDS) and Triton X-100 (TX-100). The cathodic peak potential $\left(E_{\mathrm{p}_{\mathrm{c}}}\right)$ and peak current $\left(I_{\mathrm{p}_{\mathrm{c}}}\right)$ of nicotinamide were found to be remarkably dependent on the charge and concentration of the surfactant. The presence of SDS and that of TX-100 cause a shift in peak potential and a change in peak current of nicotinamide. In the presence of the cationic surfactant, CTAB, an enhancement in the sensitivity of nicotinamide was observed. A sharp peak with more than two-fold increase in current was used to determine the limit of detection and linear working range using the differential pulse polarographic technique. The present method was successfully used for the simultaneous determination of nicotinamide and pyridoxine hydrochloride, and for the determination of nicotinamide in multivitamin pharmaceutical preparations.
\end{abstract}

(Received April 17, 2007; Accepted July 12, 2007; Published September 10, 2008)

\section{Introduction}

Nicotinamide (3-pyridine carboxylic acid amide, commonly known as niacin or vitamin $\mathrm{B}_{3}$ ) is a water-soluble vitamin that is required for cell respiration. It helps in release of energy and in metabolism of carbohydrates, fats and proteins, for proper circulation and healthy skin, in functioning of the nervous system and in normal secretion of bile and stomach fluid, so it is a pharmacologically important compound. ${ }^{1}$ A deficiency of nicotinamide causes pellagra. ${ }^{2}$ Water-soluble vitamins might, however, be lost through chemical reactions or by extraction and leaching during storage and process of food. In that sense, it is extremely important to have available preparations to replace the possible lack of the vitamins in daily diet, which is why multivitamins pharmaceuticals are becoming widely employed. So it becomes necessary to develop a simple, sensitive and reliable method to analyze nicotinamide in pharmaceutical preparations. Determination of nicotinamide has been already extensively studied by different methods like luminescence, ${ }^{3}$ surfaceenhanced Raman detection, ${ }^{4}$ reversed-phase liquid chromatography, ${ }^{5}$ micellar liquid chromatography, ${ }^{6}$ and highperformance liquid chromatography; ${ }^{7}$ however, electrochemical methods are more sensitive and simple to analyze in a complex matrix, due to nicotinamide's more negative reduction potential as compared to that of other vitamins. Also, biologically important molecules like NAD and NADH on decomposition give small amounts of nicotinamide; hence, knowledge of the electrochemical properties of nicotinamide and its reduced forms are helpful in characterization of the nucleotides. Various polarographic methods have been reported to analyze

$\dagger$ To whom correspondence should be addressed. E-mail: aksrivastava@chem.mu.ac.in; akschbu@yahoo.com nicotinamide in pharmaceutical preparations. ${ }^{8,9}$

The electrochemical behavior of nicotinamide has been reported earlier: ${ }^{10}$ it was found to be $\mathrm{pH}$-dependent. In acidic medium $^{11}$ it shows two well-defined peaks whose peak potentials are extremely close to each other. With an increase in $\mathrm{pH}$, the difference between the peak potentials decreases with decrease in current and only one peak is observed in basic medium. Sundaresan and coworker ${ }^{12}$ reported the electrochemical redox pattern of nicotinamide on a platinum electrode in acetonitrile; Santhanam and Elving ${ }^{13}$ have also reported the electrochemical redox pattern for nicotinamide species in nonaqueous medium. Its electroactivity was also determined in dimethylformamide on a glassy carbon electrode. ${ }^{14}$ Over the entire $\mathrm{pH}$ range and for all aqueous/nonaqueous solvents reported, acidic medium is the most suitable medium to study nicotinamide, but the presence of two extremely close peaks and interference of other vitamins make it difficult to analyze the trace amounts of it in complex matrix by polarography. Hence we need to develop a method for its determination in a suitable solvent.

Surface-active substances have important applications in various fields of pharmaceutical analysis. ${ }^{15}$ A widespread use of surfactants can lead to the modification of existing analytical methods. Surfactants are often used as selective masking agents to improve selectivity and sensitivity of electrochemical analysis ${ }^{16,17}$ and also play a very important role in the electrode reaction, not only in solubilizing the organic compounds but also by providing specific orientation to the molecules at the electrode interface. ${ }^{18}$ These molecules can give rise to adsorbed layers of varying thickness: monolayer, bilayer or multilayer, of a very complex structure. ${ }^{19}$ Adsorption of surfactants on electrodes and solubilization of electrochemically active compounds in micellar aggregates might significantly change the redox potential, charge transfer coefficients and diffusion 
coefficients of electrode processes, thus changing the stability of electrogenerated intermediates and electrochemical products, ${ }^{16-22}$ which becomes an advantage for its use in electrochemistry and modification of electrode. ${ }^{23}$ We have reported voltammetric behavior of certain vitamins ${ }^{24}$ (viz. menadione ${ }^{25}$ and $\alpha$-tocopherol ${ }^{26}$ ) in surfactant media. The purpose of the present work is to evaluate the effects of certain ionic and nonionic surfactants on the differential pulse polarographic behavior and the cyclic voltammetric behavior of nicotinamide, and to develop a method for its determination in pharmaceutical preparations. The surfactants used here are cetyltrimethylammonium bromide (CTAB), sodium dodecyl sulfate (SDS) and Triton X-100 (TX-100).

Nicotinamide and pyridoxine hydrochloride are the major components of pharmaceutical preparations and food products. But the adsorptive property of riboflavin on mercury electrode surface makes it difficult to study these vitamins when riboflavin is present. A method has therefore been developed for the simultaneous determination of nicotinamide and pyridoxine hydrochloride in the CTAB media. Even though various micellar electrokinetic chromatographic ${ }^{6,27-29}$ and capillary electrophoretic $^{30}$ methods have been reported for the simultaneous determination of nicotinamide along with other vitamins, no electrochemical method has been reported for the simultaneous determination of nicotinamide and pyridoxine hydrochloride in surfactant media.

\section{Experimental}

\section{Solvents and reagents}

Double distilled, deionized water was used for preparation of all solutions. The surfactants: viz. CTAB and SDS, were purchased from Loba, and TX-100 was purchased from S. D. Fine Chemicals. The vitamin nicotinamide was purchased from Lancaster and pyridoxine hydrochloride from Sigma and both were used as supplied. Mercury used for the working electrode was triply distilled under reduced pressure.

\section{Polarographic equipment}

The polarographic system used for the studies was an Electrochemical Work Station, Auto Lab 30 the electrode assembly being a 663 VA stand, with GPES computer software for recording and analyses of the polarograms supplied by Eco Chemie. Experiments were performed with a three-electrode cell consisting of a static mercury drop electrode (SMDE) as working electrode, graphite as an auxiliary electrode and $\mathrm{Ag}$ / $\mathrm{AgCl} / 3 \mathrm{M} \mathrm{KCl}$ as the reference electrode.

\section{Procedure}

Initially, differential pulse polarograms were recorded for a solution containing nicotinamide $\left(6 \times 10^{-4} \mathrm{~mol} \mathrm{dm}^{-3}\right)$ in a supporting electrolyte BR buffer ( $\mathrm{pH} 1.5 ; 0.04 \mathrm{~mol} \mathrm{dm}^{-3}$ each of acetic acid, boric acid and ortho-phosphoric acid). To the same solution an increasing concentration of cationic surfactant CTAB was added in the range of $10^{-6} \mathrm{~mol} \mathrm{dm}{ }^{-3}$, which is below the critical micellar concentration (CMC) of CTAB, to $10^{-1} \mathrm{~mol}$ $\mathrm{dm}^{-3}$, which is above the CMC of CTAB. Differential pulse polarograms were recorded after each addition at a scan rate of $10 \mathrm{mV} \mathrm{s}^{-1}$ and pulse amplitude of $100 \mathrm{mV}$. Differential pulse amplitudes from 10 to $120 \mathrm{mV}$ were tried for recording the polarograms: the current was found to increase with the increase in the pulse amplitude. However, $100 \mathrm{mV}$ was found to give the best shape and maximum peak current, as peak broadening was observed beyond it. The effects of non-ionic surfactant, TX-
100 , and anionic surfactant SDS in the same concentration range were also studied. Cyclic voltammetry was also used to study the behavior of nicotinamide in BR buffer and surfactants at different scan rates. Before each measurement, the solution was deaerated by passing a stream of pure nitrogen. All the polarographic measurements were made at $25 \pm 0.2^{\circ} \mathrm{C}$.

Simultaneous determination of nicotinamide and pyridoxine hydrochloride was carried out by differential pulse polarography. Synthetic samples having compositions of nicotinamide and pyridoxine hydrochloride in the ratios: 20:100, 20:50, 10:50 and 5:25 $\mu \mathrm{g} \mathrm{cm}^{-3}$ were prepared and their differential pulse polarograms were recorded.

\section{Preparation and analysis of samples}

The multivitamin tablets/capsule analyzed were Neurobion Forte (Merck, India), ZiComplex capsule (Mexin Medicaments Ltd., India), Omega B complex (Biotech Ltd., India), Polybion capsule (Merck, India) and $\mathrm{A}$ to $\mathrm{Z}$ antioxidants, multivitamin, multimineral tablets (Alkem Laboratories Ltd., India). In addition to nicotinamide, Neurobion Forte contained thiamine mononitrate, vitamins $\mathrm{B}_{2}, \mathrm{~B}_{6}, \mathrm{~B}_{12}$ and calcium pantothenate; ZiComplex capsule contained thiamine mononitrate, vitamins $\mathrm{B}_{2}, \mathrm{~B}_{6}, \mathrm{~B}_{12}, \mathrm{C}$, folic acid, zinc sulfate monohydrate and calcium pantothenate; Omega B complex contained vitamins $\mathrm{B}_{1}, \mathrm{~B}_{2}, \mathrm{~B}_{6}$ and $\mathrm{B}_{12}$; Polybion capsule contained vitamin thiamine mononitrate, vitamins $\mathrm{B}_{2}, \mathrm{~B}_{6}, \mathrm{~B}_{12}, \mathrm{C}$, folic acid, biotin and calcium pantothenate; Similarly, $\mathrm{A}$ to $\mathrm{Z}$ tablet contained vitamins $\mathrm{A}, \mathrm{E}, \mathrm{C}, \mathrm{B}_{2}, \mathrm{~B}_{6}, \mathrm{~B}_{12}$, folic acid, thiamine mononitrate, calcium pantothenate and some multimineral material along with it.

Each tablet or the contents of each capsule was crushed with a mortar and pestle and dissolved in the $4 \times 10^{-3} \mathrm{~mol} \mathrm{dm}^{-3} \mathrm{CTAB}$ supporting electrolyte, sonicated for $20 \mathrm{~min}$. The mixture which was then filtered through Qualigens (615) filter paper to remove traces of any undissolved matter. The filtrate was transferred to a $100 \mathrm{ml}$ flask, and diluted up to the mark with BR buffer containing $4 \times 10^{-3} \mathrm{~mol} \mathrm{dm}^{-3} \mathrm{CTAB}$. The diluted solution (12 $\mathrm{cm}^{3}$ ) was directly taken into a cell and a standard addition method was used for quantitative determination of nicotinamide by successive additions of $0.1 \mathrm{~cm}^{3}$ of standard nicotinamide solution $\left(300 \mu \mathrm{g} \mathrm{cm}^{-3}\right)$. All these samples were also analyzed by the pharmacopoeial method ${ }^{31}$ to compare with the results obtained by the above method.

\section{Results and Discussion}

\section{Behavior of nicotinamide in BR buffer}

Differential pulse polarograms of nicotinamide in BR buffer at different concentrations are shown in Fig. 1. A single broad peak is observed at lower concentration, which shifts towards more negative side with increase in concentration; above $1 \times$ $10^{-3} \mathrm{~mol} \mathrm{dm}^{-3}$ it starts showing two peaks, which are close to each other.

The electrochemical reaction for nicotinamide ${ }^{10}$ is given in Scheme I. It has been observed that nicotinamide (1) undergoes two electron exchange, initializing single electron addition to the molecule to form a neutral free radical (2) which dimerizes (3) at the sixth position; the neutral free radical again undergoes reduction to form 1,6-dihydropyridine (4). At a potential considerably more positive than that of the first reduction wave, the dimer can be oxidized back to nicotinamide and at still more positive potential, the 1,6-dihydro species also oxidized to nicotinamide. 


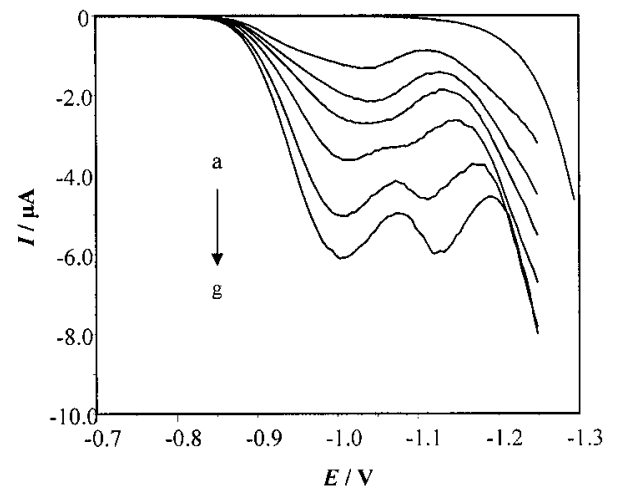

Fig. 1 Differential pulse polarograms of nicotinamide in BR buffer (pH 1.5). Nicotinamide: (a) 0.0 , (b) $3.27 \times 10^{-4}$, (c) $6.45 \times 10^{-4}$, (d) $9.52 \times 10^{-4}$, (e) $1.53 \times 10^{-3}$, (f) $2.6 \times 10^{-3}$, (g) $3.56 \times 10^{-3} \mathrm{~mol} \mathrm{dm}^{-3}$.

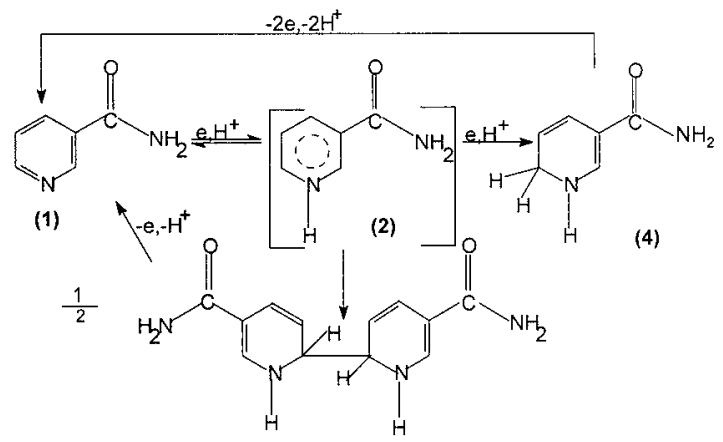

(3)

Scheme 1

\section{Surfactant effect}

Figure 2 shows the differential pulse polarogram for $5 \times 10^{-4}$ mol $\mathrm{dm}^{-3}$ nicotinamide in BR buffer $(\mathrm{pH} 1.5)$ alone and in BR buffer containing CTAB $\left(4 \times 10^{-3} \mathrm{~mol} \mathrm{dm}^{-3}\right)$ at a scan rate of 10 $\mathrm{mV} \mathrm{s}^{-1}$ and a pulse amplitude of $100 \mathrm{mV}$. The presence of CTAB surfactant results in a shift in peak potential of nicotinamide towards the more negative side with increasing in current, and this was observed until the concentration of CTAB reached to $1 \times 10^{-3} \mathrm{~mol} \mathrm{dm}^{-3}$, which was very close to CMC of CTAB $\left(9.8 \times 10^{-4} \mathrm{~mol} \mathrm{dm}^{-3}\right)$. After the CMC, with further increase in concentration of $\mathrm{CTAB}$, no change in peak potential but a very small change in peak current was noticed, in spite of the constant nicotinamide concentration. Table 1 shows the effect of concentration of CTAB on the peak potentials and peak currents for fixed concentrations of nicotinamide. The significant shift in reduction potential and the change in peak current upon addition of CTAB surfactant can be rationalized by the adsorption of the surfactant at the electrode surface, which alters the potential of the electrode and influences the electron transfer. ${ }^{32}$ It is well established that surfactant can be adsorbed on solids and on $\mathrm{Hg}$ electrodes to form surfactant films. ${ }^{33}$ In the present case, adsorption of the cationic surfactant CTAB may form a positively charged hydrophilic film on the electrode with the polar head group directed to the bulk water phase. This charged hydrophilic layer increases the concentration of nicotinamide on the electrode surface.

In BR buffer nicotinamide shows two peaks which are close to each other, whereas in the case of CTAB $\left(4 \times 10^{-3} \mathrm{~mol} \mathrm{dm}^{-3}\right)$

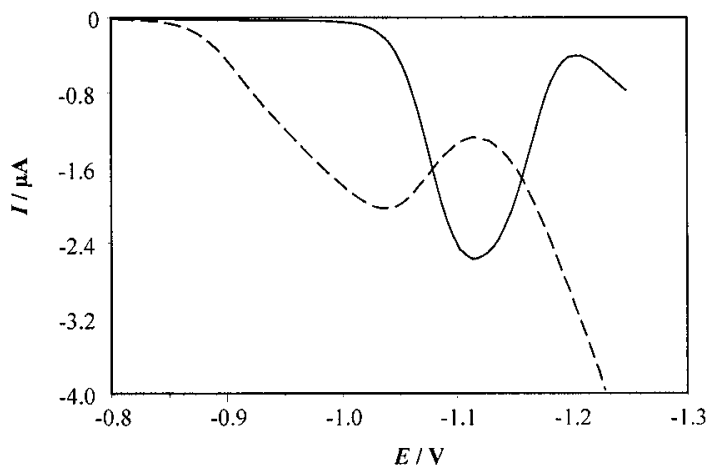

Fig. 2 Differential pulse polarograms of $5 \times 10^{-3} \mathrm{~mol} \mathrm{dm}^{-3}$ nicotinamide in BR buffer (dotted curve) and in BR buffer containing $4 \times 10^{-3} \mathrm{~mol} \mathrm{dm}^{-3} \mathrm{CTAB}$ (smooth curve).

Table 1 Effect of concentration of CTAB, TX-100 and SDS on the peak potential and peak current of nicotinamide $\left(5 \times 10^{-4}\right.$ mol $\mathrm{dm}^{-3}$ ) as obtained by DPP

\begin{tabular}{|c|c|c|c|c|c|c|}
\hline \multirow{2}{*}{$\begin{array}{c}\text { Surfactant/ } \\
\mathrm{mol} \mathrm{dm}^{-3}\end{array}$} & \multicolumn{2}{|c|}{ СТАВ } & \multicolumn{2}{|c|}{ TX-100 } & \multicolumn{2}{|c|}{ SDS } \\
\hline & $\begin{array}{c}E_{\mathrm{p}_{\mathrm{c}}} / \\
\mathrm{V}\end{array}$ & $\begin{array}{l}I_{\mathrm{p}_{\mathrm{c}}} / \\
\mu \mathrm{A}\end{array}$ & $\begin{array}{c}E_{\mathrm{p}_{\mathrm{c}}} / \\
\mathrm{V}\end{array}$ & $\begin{array}{l}I_{\mathrm{p}_{\mathrm{c}}} / \\
\mu \mathrm{A}\end{array}$ & $\begin{array}{c}E_{\mathrm{p}_{\mathrm{c}}} / \\
\mathrm{V}\end{array}$ & $\begin{array}{l}I_{\mathrm{p}_{\mathrm{c}}} / \\
\mu \mathrm{A}\end{array}$ \\
\hline 0.0 & -1.045 & 1.219 & -1.045 & 1.228 & -1.045 & 1.250 \\
\hline $1 \times 10^{-6}$ & -1.045 & 1.246 & -1.045 & 1.228 & -1.045 & 1.213 \\
\hline $3 \times 10^{-6}$ & -1.045 & 1.236 & -1.045 & 1.228 & -1.043 & 1.208 \\
\hline $5 \times 10^{-6}$ & -1.046 & 1.193 & -1.047 & 1.145 & -1.041 & 1.166 \\
\hline $1 \times 10^{-5}$ & -1.046 & 1.191 & -1.052 & 1.097 & -1.043 & 1.167 \\
\hline $5 \times 10^{-5}$ & -1.092 & 1.514 & -1.092 & 0.381 & -1.048 & 1.065 \\
\hline $1 \times 10^{-4}$ & -1.097 & 1.857 & -1.107 & 0.752 & -1.059 & 1.048 \\
\hline $4 \times 10^{-4}$ & -1.111 & 2.590 & -1.112 & 1.284 & -1.063 & 1.057 \\
\hline $1 \times 10^{-3}$ & -1.127 & 2.815 & -1.112 & 1.348 & -1.075 & 1.060 \\
\hline $5 \times 10^{-3}$ & -1.137 & 2.810 & -1.112 & 1.400 & -1.046 & 1.052 \\
\hline $8 \times 10^{-3}$ & -1.137 & 2.811 & -1.112 & 1.410 & -1.040 & 1.015 \\
\hline $1 \times 10^{-2}$ & -1.142 & 2.845 & -1.112 & 1.410 & -1.039 & 0.965 \\
\hline $5 \times 10^{-2}$ & -1.142 & 2.860 & -1.112 & 1.410 & -1.038 & 0.954 \\
\hline $1 \times 10^{-1}$ & -1.142 & 2.868 & -1.112 & 1.409 & -1.038 & 0.953 \\
\hline
\end{tabular}

surfactant, it shows a single sharp peak at $-1.127 \mathrm{~V}$ throughout the concentration range. The polarograms for different concentration of nicotinamide in $4 \times 10^{-3} \mathrm{~mol} \mathrm{dm}^{-3} \mathrm{CTAB}$ are given in Fig. 3. Please notice that the addition of CTAB to BR buffer supporting electrolyte causes an increase in the working range of the $\mathrm{Hg}$ electrode by about $100 \mathrm{mV}$ towards more negative side; this may be one of the reasons for the symmetrical shape of nicotinamide peak in CTAB surfactant medium. The calibration plots in BR buffer and in CTAB media are presented in Fig. 4. This figure shows that, in the presence of BR buffer, the calibration plot deviates from a straight line at concentrations above $6 \times 10^{-4} \mathrm{~mol} \mathrm{dm}^{-3}$ of nicotinamide, however, it shows linearity in CTAB medium. Hence, $5 \times 10^{-4} \mathrm{~mol} \mathrm{dm}^{-3}$ concentration of nicotinamide in BR buffer was chosen to study the effect of surfactant.

Cyclic voltammetry was used to study the effect of surfactant on the electrochemical behavior of nicotinamide. It showed a sharp, well-defined, completely irreversible peak in CTAB media, in comparison to plain BR buffer (Fig. 5(a)), whereas other surfactants like TX-100 (Fig. 5(b)) and SDS (Fig. 5(c)) showed ill-defined peaks shifted to the more negative side. In case of CTAB peak, potential is shifted by $\sim 15 \mathrm{mV}$ with a 


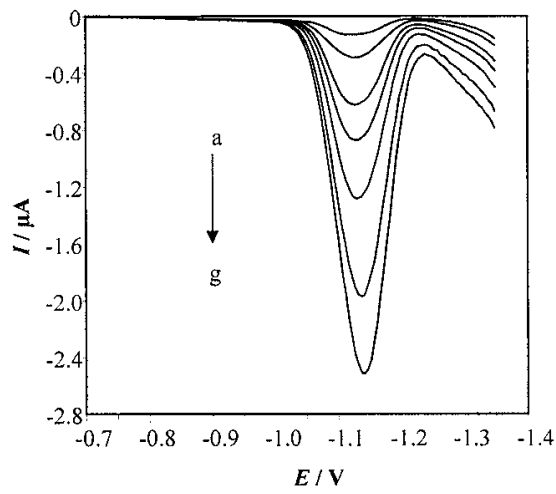

Fig. 3 Differential pulse polarograms of nicotinamide in BR buffer containing $4 \times 10^{-3} \mathrm{~mol} \mathrm{dm}^{-3} \mathrm{CTAB}$. Nicotinamide: (a) $3.25 \times 10^{-5}$, (b) $8.05 \times 10^{-5}$, (c) $1.58 \times 10^{-4}$, (d) $2.33 \times 10^{-4}$, (e) $3.42 \times 10^{-4}$, (f) $5.13 \times 10^{-4},(\mathrm{~g}) 7.01 \times 10^{-4} \mathrm{~mol} \mathrm{dm}^{-3}$.

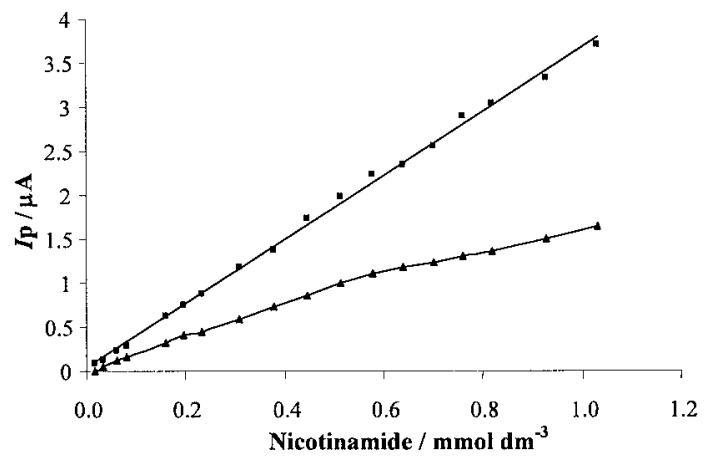

Fig. 4 Plot of $I_{\mathrm{p}} v s$. concentration of nicotinamide in BR buffer $(\boldsymbol{\Delta})$ and BR buffer containing $4 \times 10^{-3} \mathrm{~mol} \mathrm{dm}^{-3} \mathrm{CTAB}(\square)$ by differential pulse polarography.

10 -fold increase in scan rate, and the full width at half maximum and $E_{\mathrm{p}}-E_{\mathrm{p}} / 2$ values were found to be $\sim 0.068$ and $0.028 \mathrm{~V}$, respectively. The electron transfer coefficient obtained from the Tafel plot was 0.718. These mechanical parameters show that nicotinamide follows a two electron exchange reduction mechanism. The effect of scan rate at different concentrations of CTAB (Table 1) was studied. It was observed that, at every concentration of CTAB, the plots of peak current $v s$. square root of scan rate were linear, indicating that the process is diffusioncontrolled.

In the case of the neutral surfactant TX-100, with increasing addition of surfactant concentration from $10^{-6}$ to $10^{-1} \mathrm{~mol} \mathrm{dm}^{-3}$ into the cell containing nicotinamide, no changes in peak potential and peak current were observed until the concentration of TX-100 is exactly equal to CMC $\left(3 \times 10^{-6} \mathrm{~mol} \mathrm{dm}^{-3}\right)$. After the $\mathrm{CMC}$, the cathodic peak potential was shifted towards more negative side with decrease in current up to $5 \times 10^{-5} \mathrm{~mol} \mathrm{dm}^{-3}$ of TX-100 (Fig. 6). This is because of micellar formation; nicotinamide gets entrapped in the insulated hydrophobic environment of the micelle and then diffuses along with the micelle, which leads to a drop in peak current. More energy is thus required for the reduction process to occur. Similar observations are reported in the literature ${ }^{34}$ for studies on rhenium and technetium complexes. The concentration of TX100 above $5 \times 10^{-5} \mathrm{~mol} \mathrm{dm}^{-3}$ causes a new peak with an increase in peak current without much change in peak potential as the (a)

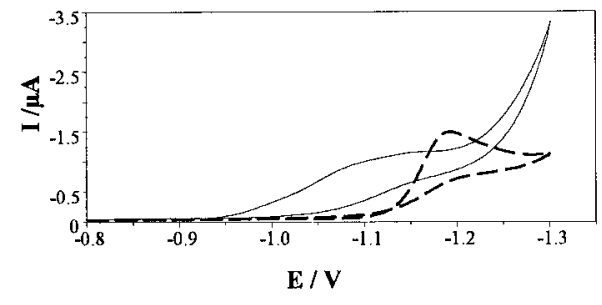

(b)

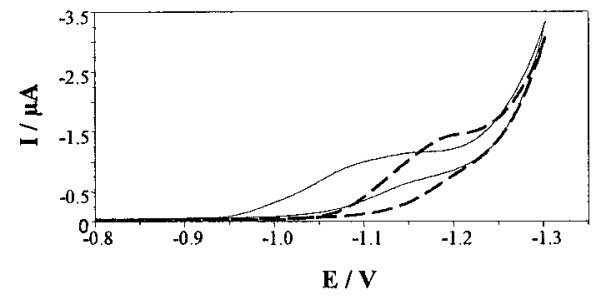

(c)

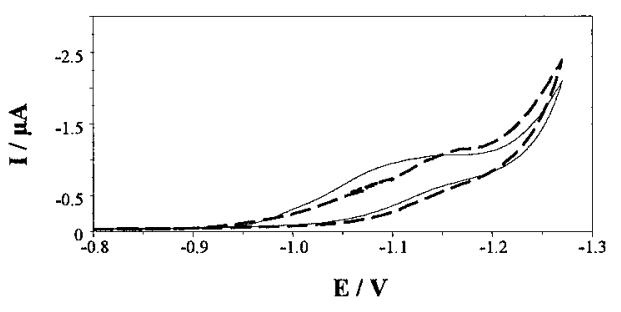

Fig. 5 Cyclic voltammograms of $5 \times 10^{-3} \mathrm{~mol} \mathrm{dm}^{-3}$ nicotinamide in BR buffer (smooth curve) and in BR buffer containing $4 \times 10^{-3} \mathrm{~mol}$ $\mathrm{dm}^{-3}$ CTAB (a), $5 \times 10^{-3} \mathrm{~mol} \mathrm{dm}^{-3} \mathrm{TX}-100$ (b) and $4 \times 10^{-3} \mathrm{~mol} \mathrm{dm}^{-3}$ SDS (c) (dotted curve).

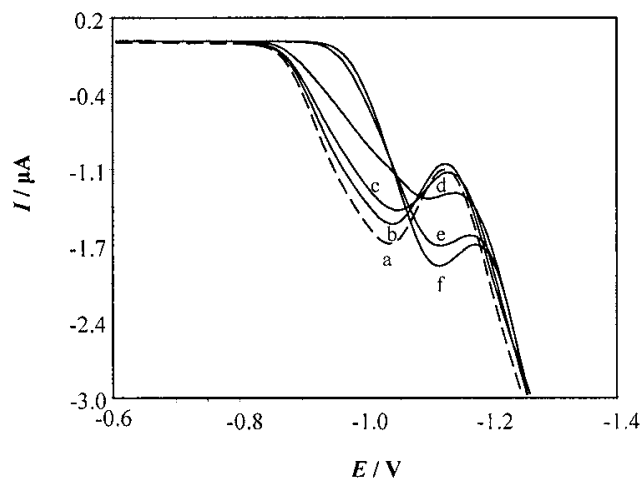

Fig. 6 Differential pulse polarogram of $5 \times 10^{-3} \mathrm{~mol} \mathrm{dm}^{-3}$ nicotinamide solution containing (a) 0.0 , (b) $5.36 \times 10^{-6}$, (c) $2.61 \times$ $10^{-5}$, (d) $5.0 \times 10^{-5}$, (e) $9.5 \times 10^{-5}$, (f) $2.1 \times 10^{-4} \mathrm{~mol} \mathrm{dm}^{-3} \mathrm{TX}-100$ in BR buffer.

micelle entrapped nicotinamide species is predominant in the solution. Above the concentration of $8 \times 10^{-3} \mathrm{~mol} \mathrm{dm}^{-3}$, the current become constant, probably because there is no change in the micelle-entrapped nicotinamide concentration.

In the case of the anionic surfactant SDS, a very interesting phenomenon was observed. With the increase in surfactant concentration, the peak potential first shifted gradually to more negative side until the surfactant concentration becomes $1 \times 10^{-3}$ 


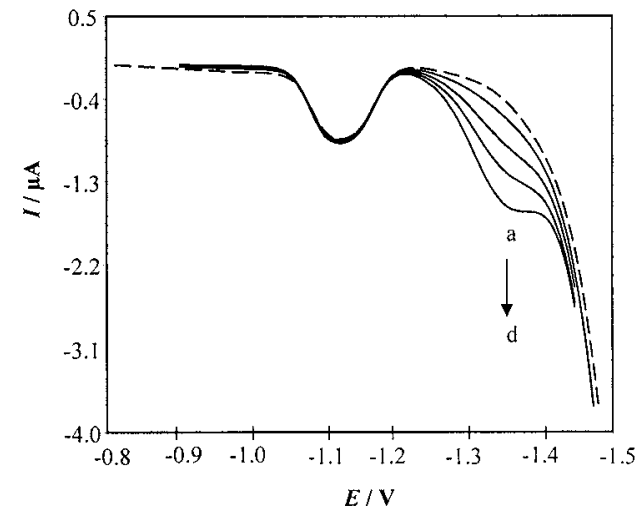

Fig. 7 Differential pulse polarograms of $20 \mu \mathrm{g} \mathrm{cm}^{-3}$ of nicotinamide (dotted curve) with pyridoxine hydrochloride: (a) 15, (b) 44, (c) 72, (d) $112 \mu \mathrm{g} \mathrm{cm}^{-3}$ (smooth curve) in $4 \times 10^{-3} \mathrm{~mol} \mathrm{dm}^{-3} \mathrm{CTAB}$.

mol dm${ }^{-3}$; with a further increase in surfactant concentration, it shifted to the positive side, returning to its original position. Peak current, however, decreased slowly with increasing concentration of SDS for a fixed concentration of nicotinamide (Table 1).

In BR buffer, nicotinamide shows two peaks with one electron exchange each, whereas surfactant medium studies revealed a single peak even at higher concentration of nicotinamide, which is probably due to the lower stability of nicotinamide free radical in surfactant medium. By comparing the effect of cationic, anionic and neutral surfactants on the electrochemical behavior of nicotinamide, we found that in all the cases there is a shift in peak potential towards more negative side, but in the cases of anionic and neutral surfactant, the nicotinamide peak merges with the background current. Hence only cationic surfactant $(\mathrm{CTAB})$ medium could be chosen for quantitative analysis of nicotinamide.

The peak current for nicotinamide in CTAB medium is sharper with $\sim 2.3$ fold increase in current compared to BR buffer. This enhancement in CTAB over BR buffer increases to more than 3 fold at higher concentrations of nicotinamide because of the presence of a single well-defined peak throughout the working range (Fig. 4). This observation has been utilized for its determination. Therefore, a linear working range of nicotinamide was found to be $1.64 \times 10^{-6}$ to $8.18 \times 10^{-3} \mathrm{~mol}$ $\mathrm{dm}^{-3}$ with a detection limit of $1.64 \times 10^{-7} \mathrm{~mol} \mathrm{dm}^{-3}$ in $4 \times 10^{-3}$ mol dm${ }^{-3}$ CTAB medium. The detection limit which is observed by present method is much lower than that for a recently reported method $\left(3.3 \times 10^{-7} \mathrm{~mol} \mathrm{dm}^{-3}\right){ }^{35}$ The enhanced peak with lower detection limit observed in surfactant medium (CTAB) helps in determination of nicotinamide in different pharmaceutical samples.

\section{Interference study and simultaneous determination of vitamins}

The interferences by other vitamins were studied. Vitamins $\mathrm{B}_{1}, \mathrm{~B}_{2}, \mathrm{~B}_{6}, \mathrm{C}$ and PABA are the major components of multivitamin pharmaceutical preparations over nicotinamide peak. In BR buffer no peak was observed for nicotinamide in the presence of riboflavin; this was due to adsorptive property of riboflavin on the electrode surface, which inhibited the reduction of other ions on the same electrode surface. This was confirmed by taking synthetic samples of mixtures of nicotinamide and riboflavin. We observed here that the presence of small amounts of riboflavin leads to disappearance of nicotinamide peak. Similarly, in BR buffer it was found that the background current
Table 2 Accuracy and precision of the method for simultaneous determination of nicotinamide and pyridoxine hydrochloride in BR buffer at $\mathrm{pH} 1.5$ containing $4 \times 10^{-3} \mathrm{~mol}$ $\mathrm{dm}^{-3}$ CTAB by DPP

\begin{tabular}{|c|c|c|}
\hline \multirow{2}{*}{$\begin{array}{l}\text { Synthetic sample, } \\
\text { nicotinamide: } \\
\text { pyridoxine } \mathrm{HCl} / \\
\mu \mathrm{g} \mathrm{cm}^{-3}\end{array}$} & \multicolumn{2}{|c|}{ Recovery } \\
\hline & $\begin{array}{c}\text { Nicotinamide/ } \\
\mu \mathrm{g} \mathrm{cm}^{-3}\end{array}$ & $\begin{array}{c}\text { Pyridoxine } \mathrm{HCl} / \\
\mu \mathrm{g} \mathrm{cm}^{-3}\end{array}$ \\
\hline 20:100 & $20.0 \pm 0.4$ & $100.1 \pm 0.7$ \\
\hline $20: 50$ & $20.0 \pm 0.4$ & $50.1 \pm 0.5$ \\
\hline $10: 50$ & $10.0 \pm 0.2$ & $50.1 \pm 0.5$ \\
\hline $5: 25$ & $5.1 \pm 0.2$ & $25.1 \pm 0.4$ \\
\hline
\end{tabular}

$n=5$.

merges with the nicotinamide peak at higher concentrations of nicotinamide. Also, pyridoxine hydrochloride peak $(-1.385 \mathrm{~V})$ is found very close to the decomposition potential of BR buffer. Therefore, only BR buffer is not a good medium for simultaneous determination of nicotinamide and pyridoxine hydrochloride. However, the presence of surfactant overcomes these limitations. It was observed that nicotinamide showed a well-defined sharp peak at the same potential $(-1.127 \mathrm{~V})$ in $\mathrm{CTAB}$ in presence and absence of riboflavin. This may be due to adsorption of surfactant of varying thickness on the electrode surface, ${ }^{19}$ which inhibited the adsorption of riboflavin on the electrode surface. The presence of other vitamins like $\mathrm{B}_{1}, \mathrm{~B}_{6}, \mathrm{C}$ and PABA did not affect the peak potential and peak current of nicotinamide even when present in a 100 fold excess concentration. The increase in working range of $\mathrm{Hg}$ electrode and the symmetrical shape of nicotinamide peak observed in $4 \times$ $10^{-3} \mathrm{~mol} \mathrm{dm}^{-3}$ CTAB made simultaneous determination of nicotinamide and pyridoxine hydrochloride possible.

Figure 7 shows differential pulse polarograms of simultaneous determination of nicotinamide $\left(20 \mu \mathrm{g} \mathrm{cm}^{-3}\right)$ and varying concentration of pyridoxine hydrochloride in $4 \times 10^{-3} \mathrm{~mol} \mathrm{dm}^{-3}$ CTAB medium. These results indicate that simultaneous determination of nicotinamide and pyridoxine hydrochloride was possible only when pyridoxine hydrochloride concentration is more than that of nicotinamide. Synthetic samples containing different compositions of nicotinamide and pyridoxine hydrochloride were analyzed; in these the peak current and the peak potential of nicotinamide were observed to be same as those obtained for pure nicotinamide solution with the same concentrations. Table 2 compares the actual and observed contents for nicotinamide and pyridoxine hydrochloride in mixtures of different proportions.

\section{Determination of nicotinamide in different sample}

Maintaining the same experimental conditions, pharmaceutical preparations having a complex matrix were analyzed by a standard addition method; the results are given in Table 3. The contents of nicotinamide in these samples determined by the present method are in good agreement with the labeled specifications. The results show that the determination of nicotinamide in pharmaceutical samples by DPP in $4 \times 10^{-3}$ mol $\mathrm{dm}^{-3} \mathrm{CTAB}$ is better than in BR buffer due to its sensitivity, well-defined sharp single peak and lower detection limit. The results obtained for pharmaceutical samples by this method were also compared with the results obtained by a pharmacopoeial method, and found to be in good agreement with each other (Table 3). 
Table 3 Assay of nicotinamide in pharmaceutical preparations

\begin{tabular}{lccc}
\hline \multirow{2}{*}{\begin{tabular}{c} 
Sample \\
\cline { 3 - 4 }
\end{tabular}} & $\begin{array}{c}\text { Quoted } \\
\text { content/mg } \\
\text { (cap/tablet) }\end{array}$ & $\begin{array}{c}\text { DPP } \\
\text { technic/mg } \\
\text { (cap/tablet) }\end{array}$ & $\begin{array}{c}\text { Observed content } \\
\text { method/mg } \\
\text { (cap/tablet })^{-1}\end{array}$ \\
\hline Zi complex capsule & 50.0 & $49.9 \pm 0.8$ & $49.9 \pm 0.8$ \\
Neurobion Forte & 45.0 & $45.0 \pm 0.4$ & $45.0 \pm 0.5$ \\
A to Z tablet & 50.0 & $50.0 \pm 0.5$ & $50.1 \pm 0.8$ \\
Omega B complex & 15.0 & $15.1 \pm 0.3$ & $15.1 \pm 0.6$ \\
Polybion tablet & 100.0 & $99.7 \pm 0.5$ & $99.5 \pm 0.7$ \\
\hline
\end{tabular}

a. $n=5$.

\section{Conclusions}

The electrochemical behavior of nicotinamide in the presence of different kind of surfactants shows that both the charge and concentration of the surfactant can influence its response. A strong adsorption of CTAB on $\mathrm{Hg}$ electrode surface prevents adsorption of other organic molecules, which helps in determination of nicotinamide in a complex matrix. The welldefined sharp peak observed in the present method for nicotinamide in CTAB media can be successfully applied for its determination in pharmaceutical preparations.

\section{Acknowledgements}

The Department of Science and Technology, Govt. of India, is thanked for providing the financial assistance for this work.

\section{References}

1. J. Yang and J. D. Adams, Drug Design Reviews, 2004, 1, 43.

2. F. Bicknell and F. Prescott, "The Vitamins in Medicine", 2nd ed., 1947, William Heinemann, London.

3. A. I. Krasnova, M. P. Aguilar-Caballos, and A. GómezHens, Anal. Chim. Acta, 2001, 441, 249.

4. T. Pal, V. Anantha Narayanan, D. L. Stokes, and T. V. ODinh, Anal. Chim. Acta, 1998, 368, 21.

5. P. Vinas, C. Lopez-Erroz, N. Balsalobre, and M. Hernandez-Cordoba, J. Chromatogr., A, 2003, 1007, 77.

6. L. Monferrer-Pons, M. Elisa Capella-Peiró, M. Gil-Agustý, and J. Esteve-Romero, J. Chromatogr., A, 2003, 984, 223.

7. Z. Chen, B. Chen, and S. Yao, Anal. Chim. Acta, 2006, 569, 169.

8. H. M. Gonzaelez, C. J. Costa, J. Alpizar, and G. Font, Cienc. Pharm., 1993, 3, 152.
9. E. Jacobsen and K. B. Thorgersen, Anal. Chim. Acta, 1974, $71,175$.

10. P. J. Elving, J. E. Oreilly, and C. O. Schmakel, "Method of Biochemical Analysis", 1973, Vol. 21, John Wiley and Sons, 337.

11. R. M. Galvin and J. M. R. Mellado, J. Electroanal. Chem., 1989, 260, 101

12. N. S. Sundaresan, V. Swayambunathan, and K. S. V. Santhanam, Trans. SAEST, 1978, 13, 193.

13. K. S. V. Santhanam and P. J. Elving, J. Am. Chem. Soc., 1973, 95, 5482.

14. S. Berchmans and R. Vijayavali, Bull. Electrochem., 1996 , 12,411 .

15. M. Jelikic-Stankov, P. Djurdjevic, Z. Radovic, and D. Malesev, Arhiv za Farmaciju, 1995, 45, 41.

16. T. F. Connors, J. F. Rusling, and A. Owlia, Anal. Chem., 1985, 57, 170 .

17. M. Stadiober, K. Kalcher, G. Raber, and C. Neuhold, Talanta, 1996, 43, 1915.

18. P. G. Westmoreland, R. A. Day, and A. L. Underwood, Anal. Chem., 1972, 44, 737.

19. M. J. Rosen, "Surfactants and Interfacial Phenomena", 1978, Wiley Interscience, NewYork.

20. X.-L. Wen, Y.-H. Jia, and Z.-L. Liu, Talanta, 1999, 50, 1027.

21. P. A. Quintela and A. E. Kaifer, Langmuir, 1987, 3, 769.

22. Y. Oshsawa and S. Aoyagui, J. Electroanal. Chem., 1982, 136, 353.

23. R. Vittal, H. Gomathi, and K.-J. Kim, Adv. Colloid Interface Sci., 2006, 119, 55

24. P. V. Jaiswal, V. S. Ijeri, and A. K. Srivastava, Anal. Sci., 2001, 17, i741

25. P. V. Jaiswal, V. S. Ijeri, and A. K. Srivastava, Bull. Chem Soc. Jpn., 2001, 74, 2053

26. P. V. Jaiswal, V. S. Ijeri, and A. K. Srivastava, Anal. Chim. Acta, 2001, 441, 201.

27. H. Okamoto, T. Nakajima, and Y. Ito, J. Chromatogr., A, 2003, 986, 153.

28. H. Okamoto, T. Nakajima, and Y. Ito, J. Pharm. Biomed. Anal., 2002, 30, 815.

29. Q. Dang, Z. Sun, and D. Ling, Yaowu Fenxi Zazhi, 1992 12, 273.

30. M. Schreiner, E. Razzazi, and W. Luf, Nahrung, 2003, 47, 243.

31. Indian Pharmacopeia, Vol. I, 1996, The Controller of Publications, Delhi, 508.

32. N. Batina, B. Cosovic, and R. Adzic, J. Electroanal. Chem., 1985, 184, 427

33. J. F. Rusling, N. Hu, H. Zhang, D. J. Howe, C. Miaw, and E. C. Couture, Electrochem. Colloids Dispersions, 1992, 303

34. J. R. Kirchhoff, E. Deutsch, and W. R. Heineman, Anal Lett., 1989, 22, 1323.

35. X. Wang, N. Yang, and Q. Wan, Electrochim. Acta, 2006, 52,361 